\title{
AMUSI ODI
}

\section{Creative Research and Theory Building in Library}

\section{and Information Sciences}

\begin{abstract}
This paper is a critique of the prevalent conceptual methodologies in research in library administration. It examines the current research methodologies found mostly in Dissertation Abstracts International (University Microfilms International), relates them to the positivistic orientation of some social scientists, indicates why they are inappropriate, and suggests how research in library administration can be made more meaningful and relevant.
\end{abstract}

A

SEMINAL EVENT took place in May 1968 when sociology students at the University of Nantes, France, violently demonstrated against the government of their country. The students presented the French government with a document entitled, "Why Sociologists?" in which they demanded radical changes in sociology studies in France. ${ }^{1}$ The focus of the protest was the type of sociology taught in French universities: the students viewed it as patently oriented to the defense of the status quo.

This protest was not new except that it took a different pattern from earlier ones. Also, it was for a slightly different reason. The development of approaches to the study of social phenomena has, since antiquity, deeply troubled many critical minds. Since the period of the Greek scholars, members of the academic community have insisted on truth and honesty in all matters of scholarship. They have insisted that knowledge must mean "proven knowledge"; proven either by practical, empirical demonstration or by the logic of reason. It was felt that scholars have a responsibility to ensure that, even in thought, the gap between knowledge

Amusi Odi is program director at the Institute of Training and Organizational Development, Graduate School of Public and International Affairs, University of Pittsburgh. and speculation is reduced to a minimum.

How, then, do we arrive at proven knowledge? A school of thought, generally identified by the name "positivism," contends that nothing that is not practically demonstrable can be regarded as truth. As Richard Sonnet aptly expressed it, "To touch, to measure, and then to talk about the meaning of what one had touched: This process was the guiding principle of positivism."2

Positivism insists that the methods of the natural sciences are appropriate in the study of social phenomena. Why? Because the pursuit of truth and the discovery of reality both demand that the investigator hold his personal feelings, biases, preconceptions, and the like, in abeyance; they must never be allowed to interfere with the discovery of reality. Even his sympathetic disposition toward the human condition must not be permitted to interfere with empirical evidence. Alfred Schultz put it this way: "While the theorist may be passionately interested in the fate and quality of social and political life, he must bracket this practical interest in his pursuit of theory." ${ }^{3}$ It is this insistence that the methods of the natural sciences are applicable to the study of social phenomena that Richard Sonnett calls "human empiricism." 4

But "human empiricism" has not been left unchallenged. This challenge was spearheaded by German and Italian students of 
society. The German historian Wilhelm Dilthey observed that we notice, touch, and measure only those things we already have the conviction are real; and the great Italian philosopher Beneditto Groce was puzzled by the insistence of empiricists that a science of man start with an inhuman premise, namely, that the scientist could set aside his or her own beliefs, feelings, and sense of reality. ${ }^{5}$

Other aspects of the challenge have been added in recent years. For instance, the American social theorist J. O. House contends that positivism is grossly inapplicable to the study of human society on at least two grounds. In the first place, the investigator himself is part of the subject matter that he is investigating and cannot, therefore, be objective and value free in the way that a natural scientist is presumed to be. Secondly, man is a different kind of phenomenon from the rest of nature in that his behavior is mediated by subjectively ascribed meanings that cannot be observed by the investigator. ${ }^{6}$

William McBride even goes so far as to argue that "the whole idea of social science, given the meanings of the word science in contemporary English, is a mistake." 7 This may be something of an overstatement, but it has relevance in the context of current approaches to social science research. The whole notion of social science as a "science of society" leads, in the opinion of this writer, to unacceptable methodological trends in the study of human activities.

\section{Purpose of Research}

Let us go back to the fundamental question: What is the purpose of research? It seems to me that, briefly stated, the sole purpose of research is the development of theory. But what is theory? The French philosopher Francois Marie Arouet, known to history as Voltaire, once told his listeners, "If you wish to converse with me, define your terms." We would thus define theory here as an internally connected and logically consistent proposition about relationship(s) between phenomena. In essentially all circumstances, a theory is an explanation of an observed relationship between phenomena. A theory always seeks to account for an observed event given specified circumstances.

A theory is different from law, which
House defines as "an empirical generalization that is held to be INVARIANT given specified conditions." ${ }^{9}$ Both theory and law are explanations of observed events; but, unlike law, a theory is never held to be invariant, however stringent its specified conditions. A theory can easily be falsified by a new discovery or by a reinterpretation of its crucial propositions. ${ }^{10}$ One is easily reminded of various theories that at one time provided plausible explanations of various phenomena in nature but were later superseded as more sophisticated and reliable instruments and techniquebwere discovered or invented. For illustrative purposes, let us confine ourselves to one area: library and information science research.

\section{EMERGING TRENDS IN LIBRARY AND INFORMATION SCIENCE}

A disturbing trend pervades library and information science and, in fact, most studies in the social sciences today. This trend is quantification of human behavior. This quantification arises from the mistaken belief that reality can only be discovered through hard data; worse still is the prevailing tendency to assume that mathematical or statistical values explain reality and that social theories can be derived from them. Space does not permit a comprehensive survey of the whole spectrum of library and information science research nor will such a comprehensive survey serve the intended purpose of this paper. We will, therefore, concentrate on one area of library and information science research: library administration.

A careful look at Dissertation Abstracts International published during the last ten years on library administration reveals three areas of concentration. These three areas correspond roughly with three leadership theories. Briefly, they are: (1) PersonalityCharacter Trait Theory, which emphasizes personality and character traits as the key elements in leadership; (2) Institutional Theory, which contends that the library system, over time, infuses its leaders with specific values. The individual administrator usually concerns himself with human interaction and communication, with persons, and with his own contribution to the efficiency of the library system. In the course of time, the administrator must conform to institutional ex- 
pectations. Library administrators who view the library as a system thus differ from other administrators who do not; and (3) the Situational Theory, which holds that both the character of the individual administrator and the situation in which he finds himself determine, or should determine, his administrative practice.

The prevailing research practice is to elicit data on a given administrative style of individual administrators. Such data are usually derived by means of a questionnaire from such instruments as Rensis Likert's "Linking Pin," which tries to determine how "participative" an administrator is or Tannenbaum and Schmidt's "Continuum of Leadership Styles," which, like the "Linking Pin," measures leadership style.

The resulting data on the administrative practice of a given administrator are then correlated with one or other administrative styles; if the correlation is significant, the conclusion generally drawn is that the administrator's leadership style is either authoritarian, democratic, or laissez-faire. Certainly this apparently whimsical illustration may seem trite, but it contains the substance of most of what one encounters in most researches in library administration.

Even on the analytic ground alone, correlation would still be inappropriate in comparison with multivariate regression analysis; in fact, regression analysis provides more information than correlation in that it answers correlation questions, is a stronger method of inference, and demands less stiff assumptions. As Choucri and North skillfully observed, "Correlation is useful primarily as an aid to understanding regression and as an auxiliary tool; correlation gives no indications concerning cause and effect; it gives only one number as an aid towards understanding a complex relationship rather than the estimation of a mathematical function yielded by regression techniques; it demands more restrictive assumptions concerning the distribution of the data than does regression; and it does not tell us how two variables move together." 11

But empirically oriented researchers would not permit the consideration of analytic propriety to stand in their way. The important thing, they seem to contend, is to accumulate data on administrative behavior, correlate these data, and show relationships among them.

This practice, regrettably, has led to what the structural anthropologist Levi Strauss terms "the inductive illusion": the belief that reality can be discovered by the accumulation of more and more data and the examination of more and more cases. Empiricists persuade themselves to believe that if they gather more and more data and establish more and more associations, they can develop theories of administration. This, to say the least, is a fallacy. A theory is not built by a mere accumulation of data. As Kenneth Waltz observed:

If we gather more and more data and establish more and more associations . . . we will not finally find that we know something. We will simply end up having more and more data and larger sets of correlations. Data never speak for themselves; observation and experience never lead directly to knowledge of causes. ${ }^{12}$

The source of this fallacy is a failure by researchers to distinguish between description and explanation. Statistics are descriptions in numerical form: if we find a strong statistical association between a library administrator's management style and a given administrative instrument, it would be wrong for us to conclude that we have accounted for the management style in the sense of explaining it. Numbers, as Waltz notes, "may describe what goes on in the world"; they do not explain it.

Statistical associations alone can never lead to the development of a theory. Waltz is right when he contends that "a theory is not the occurrences seen and the associations recorded, but is instead the explanation of them."13 Even if Galileo's claim that nature writes its secrets in numbers is true, it is still necessary for men to unravel these numbers in the form of words.

\section{Theory BUILDING}

How, then, is a theory built? How, specifically, can a theory of library administration be built? In a broader perspective, the question might be put this way: How can a theory of administration be built?

Earlier, we defined theory as an internally connected and logically consistent proposition about the relation(s) between phenomena. A theory is a product of an abstraction 
from empirical data, not a generalization from the data. A theory is born at the moment when a researcher abstracts from observed data and tries to discern general patterns that connect them. The act of abstracting is an active process; it involves a deliberate attempt to invoke flashes of new perception. This is not easy. Ideas do not materialize on demand; worse still, ideas often begin in vague, undefined forms. As Fred Hoyle remarks:

It is not only difficult to come by our flashes of new perception, but no two of us have flashes exactly in the same direction. Even if you should suddenly see a point in some particular problem or other ... you've still got the job of convincing the rest of us. ${ }^{14}$

What Hoyle refers to as "the job of convincing" others is the organization of the new flashes of ideas into a logically consistent form: re-creating reality from the abstractions of sense impressions. It is this organization of ideas that Berdyaev calls "marriage" or a "meeting between different elements." The researcher brings together his personal, creative conception with his empirical observation to create a third thing, the offspring of this union: a theory. Theory creates unity from diversity; it imposes simplicity, order, and regularity on complex, disorderly, and apparently anomalous phenomena.

In all circumstances, even if implicitly, theory, as Robin Horton reminds us, "places things in a causal context wider than that provided by common sense." 15 An illustrative example is Max Weber's "Protestant Ethic." Weber's starting point was a statistical survey, carried out in 1900 by German sociologist Max Offenbacher, into "the economic condition of Catholics and Protestants" in the religiously mixed (60 percent Catholic) grand duchy of Baden. Offenbacher established that the Protestant citizens of the grand duchy owned a disproportionately large percentage of capital assets and had more than their fair share of leading positions, educational qualifications, academic positions, and skilled labor jobs. ${ }^{16}$ Weber went beyond a mere description of Offenbacher's data and abstracted from it by asking himself to what combination of circumstances the following fact should be attributed: "Business leaders and owners of capital, as well as the higher grades of skilled labor, and even more the higher technically and commercially trained personnel of modern enterprises, are overwhelmingly Protestant." 17 He postulated that the answer to his rhetorical question must be located in the doctrinal foundation of Calvinistic Protestantism (Protestant Ethic).

Formal logic is based on this process. Principles of logic presume that putting together known truths in specially formulated ways yields new truths. This is the basis of Aristotelian syllogism, which, in its simplest form, is generally stated thus:

Every man dies

Socrates is a man

Therefore Socrates will die.

In this way, a person may move reasonably from the known to the unknown by organizing empirical data in a certain manner and then, on the basis of these data, deducing a generalization.

The major distinction between formal logic and creative abstracting lies in how the combination process goes. Formal logic virtually predetermines its conclusions by distinctive patterns of movement. Creative abstracting, on the other hand, is much less rigid and, therefore, much less certain in its conclusion - but generally more open to discovery. A person takes a certain amount of risk in combining ideas. He will be uncertain how fruitful the synthesis will be, yet the chances are high that some fruitful abstracting will ensue. It is this critical abstracting that students of Marxism refer to as dialectics. Dialectical analysis, in the context of administration, begins with a given administrative style as it is observed (thesis), examines its opposite or negation (antithesis), and postulates, by a logical examination of all available information, the development of a new approach that will overcome the defects of the existing administrative style (synthesis).

Most researchers in library administration do not go beyond the stage of antithesis or negation. Negation itself is viewed by students of dialectical orientation merely as a step towards a radical rejection of the status quo. It is not the analytic conclusion, for it yields nothing other than the rejection of an existing system. Negation, considered as an analytic end, is a fruitless effort, for actions do not lie in the act of negation, but in proposi- 
tions that lead to overcoming an observed defect. A social change activist who rejects (or negates) all existing systems is not contributing to social progress unless and until he, by a conscious act of will, proposes an alternative path to change that is born out of a careful analysis of both the existing order and its alternatives. It is this critical, analytic synthesis that gives birth to fruitful abstracting.

Creative abstraction is not easy nor is it very common. As Carl Rogers observes:

In the sciences, there is an ample supply of technicians, but the number who can creatively formulate fruitful hypotheses and theories is small indeed. ${ }^{18}$

Creative abstracting takes a considerable amount of personal conviction and commitment. This, contrary to what human empiricists would like us to believe, applies to both the natural and the social sciences. In his book, Personal Knowledge, Michael Polanyi makes it clear that even scientific knowledge is personal knowledge, committed knowledge. It is erroneous to believe that scientific knowledge is impersonal and "out there," that it has nothing to do with the belief of the individual who has discovered it. Instead, every aspect of science is pervaded by disciplined personal commitment, and Polanyi makes the case very persuasively that the whole attempt to divorce science from the person is a completely unrealistic one. Perhaps a brief quotation will provide the flavor of his thinking:

So we see that both Kepler and Einstein approached nature with intellectual passions and with beliefs inherent in these passions, which led them to their triumphs and misguided them to their errors. These passions and beliefs were theirs, personally, even though they held them in the conviction that they were valid, universally. ${ }^{19}$

It is evident that reality cannot be discovered by merely accumulating empirical data on human behavior. In the particular case of library administration, aggregation of empirical cases of administrative styles and practices cannot advance the understanding of library administration, nor can it lead to the development of a viable theory of administration. To develop a viable theory of administration, the researcher must go beyond the empirical data before him: he must combine what is already known in the field with his perception of the problem before him to develop a new and unique way of viewing the problem. A descriptive account of observable administrative behavior is only a beginning - an explanation must be sought as to why the individual chooses that specific style of administration, what environmental and other conditions facilitate or hinder the choice, and how that choice relates to the individual's social, economic, political, and cultural predispositions. The objective is the development of a theory or theories of administration that furnish us with what type of person tends to practice what style of administration under what type of social, economic, political, and cultural circumstances. It would then be possible to realize how social, economic, trait, political, and cultural factors influence or determine administrative practices.

The goal would be to arrive at a nomological universal generalization about administrative styles and practices and factors that influence them. We would then be in a position to say: "Given the following factors, put this person in this institution, organization, or agency."

It is important here to elaborate a bit on the nature of nomological generalizations. Generalizations may be conveniently grouped into three major categories: nomological universal, prevalence, and probabilistic. ${ }^{20}$ We will use, for example, the statement, "Experienced librarians who also worked as social workers make good library administrators at the village level." The three types can be expressed as follows: a nomological universal generalization (all experienced librarians who also worked as social workers make good library administrators at the village level); a prevalence generalization (generally or normally experienced librarians who also worked as social workers make good library administrators at the village level); and a probabilistic generalization (the probability that an experienced librarian who also worked as a social worker will make a good library administrator at the village level is 90 percent).

From the above examples it is evident that a nomological universal generalization is a proposition that refers to an indefinite number of instances. Such universal generalizations cover every case. A nomological univer- 
sal generalization is very difficult to attain, but it must constitute the goal of research because, as Phillips has noted, "It is [only] the nomological type [of generalization] which has the necessary validity for prediction and control." ${ }^{21}$ Both the prevalence and probabilistic generalizations contain elements of uncertainty. As an objective (short-term measure), both may be adequate, but, in the long run, the goal of all research must be the attainment of nomological universal generalizations.

How can nomological universal generalizations be attained? Different people tend to behave differently in identical situations. How can we validly arrive at a universal generalization that refers to an indefinite number of instances? The key lies, in this author's view, in two factors: data gathering and the meanings we assign to terms.

\section{Data Gathering}

To validly arrive at nomological universal generalizations, research data must be allembracing. This means that data must be derived from a large variety of sourcessources that have even the remotest theoretical probability of affecting the subject under study. In the specific case of library administration, data must be derived from all possible factors that can affect a given administrator's behavior. Data sources must include, as a minimum, the administrator's socioeconomic status, political orientation, health condition, age, educational level, and cultural memory.

The approach must, as we have seen, be dialectical-using dialectics in Sherman's sense to denote "an approach to problems that visualizes the world as an interconnected totality." 22 It is not enough to have an administrator simply fill in a questionnaire and to draw a conclusion from a descriptive analysis of his responses. Research findings in this case must always be probabilistic at best since the administrator's behavior is merely described, not explained.

Here is where positivism may be wrong, since a large part of what influences behavior may be, and generally is, practically unobservable. Observable behavior is generally a function of two factors: stimulus and attitude. Stimulus gives rise to attitude; observable behavior is a manifestation of attitude.
By relying entirely on observable behavior as the ultimate source of reality, positivists or "human empiricists" tend to approach reality from a superficial standpoint. They forget that every behavior has a meaning for the behaver and that no satisfactory explanation of a behavior can be arrived at unless we take into consideration the motivations and intentions of the behaver. Besides, any single behavior may have been motivated by an immense number of unobservable factors. As Lakatos observed, "Any explanation [based on observed behavior] is only approximate, because of the infinite complexity of the factors involved in determining any single event."23

\section{Meaning in Language}

All words have both assigned meaning, sometimes called connotation, and specific area of application, sometimes called denotation. Phillips ${ }^{24}$ has shown that most statements usually labeled "factual" by researchers are actually characterized by multiple meanings, some factual, some valuative. His illustrative example is a statement such as, "Democracy is a better form of government than communism." Phillips has shown that this deceptively simple statement may mean any of four things: (1) an approval of democracy by the speaker; (2) an attempt by the speaker to persuade his listeners to change their attitudes in favor of democracy and against communism; (3) a belief by the speaker in the factual accuracy of his statement and his right to persuade others to accept it; and (4) the speaker's willingness to listen to counterarguments with a belief that he can withstand them.

It is inconceivable that we can achieve nomological universal generalizations in research unless we use words so precisely that the meanings we assign to them are clear and unambiguous. It would be much more helpful if the maker of the statement "Democracy is a better form of government than communism" defined not only what he meant by "good" government, but also the kind of behavior he considers democratic, under what circumstances such characteristics should be regarded as good, and under what circumstances they cease to be termed good. For example, two individuals may seem to agree on the field of its application (denotation). They 
may agree that whatever increases the happiness of a given social unit is good, but one of them may disagree that a victorious war of conquest qualifies as "good." When researchers talk about "participative management," the term almost invariably means different things to different people. Does a library administrator who consults his staff in all cases of policy, but who nevertheless issues instructions that reflect his private, personal decision, practice participative management? Does a library administrator who does not consult with his staff in a formal way, but whose decisions invariably reflect the interest of the staff, fail to practice participative management? What specifically is "participative management?"

If we accept, as the fundamental purpose of research in administration, the discovery of basic invariants, structures or laws (given specified conditions) that can serve as a proposition that will take a deductive form, and from which we can derive counterfactual claims about the relations of individual traits, unique situation or environment, institutional variables, and administrative style, then the language we use in research reports must be so precise that the probability of both connotative and denotative ambiguity, if not completely eliminated, is reduced to an absolute minimum.

\section{Conclusion}

The insistence by researchers on strict ob- servance of the law of evidence is legitimate and indisputable. What is and has been disputable is what constitutes evidence. Human empiricists contend that only the practical and observable can legitimately be entitled to a claim of legitimacy. Others are not so sure. They argue that empiricism tends to lead to quantitative bias as well as reductionism, which emphasizes a theoretical framework of hypothesis over total experience. Besides, quantitative bias tends to mistake description for explanation. The aim of research is to provide explanation of the relationship between phenomena in nature. When research is purely descriptive or when it takes the form of a typology of a given phenomenon, the description or typology is only an aid to eventual explanation and understanding of the phenomenon under study.

Empirical research in library administration, particularly as it is reported in Dissertation Abstracts International, is becoming something of a ritual. It is typified by the use of essentially the same pattern of instrument to determine the administrative style of a variety of library administrators. The conclusions give the impression of a litany, sounding essentially the echo of studies done several years ago and contributing nothing in the way of theory building.

This paper is an appeal for creativity in library research. "Not that again," as the writer and cognitive theorist Jerome Bruner observed, "is a sign of dismay."

\section{REFERENCES}

1. William L. McBride, "Student Power," in his Social Theory at a Crossroads (Pittsburgh: Duquesne Univ. Pr., 1980), p.17.

2. Richard Sonnet, "The Absolute Truth about Mankind," New York Times Book Review (9 Sept. 1979), p.9, 43.

3. Richard Bernstein, The Structure of Social and Political Theory (New York: Harcourt, 1976), p.173.

4. Sonnet, "The Absolute Truth,"p.9.

5. Ibid., p. $9,43$.

6. J. O. House, "A Note on Positivism," Insurgent Sociologist 6, no.2:94-95 (1976).

7. McBride, Social Theory, p.12.

8. Quoted in Will Durant, The Story of Philosophy (New York: Simon \& Schuster, 1961), p.48.

9. House, "A Note," p.96.
10. Some scholars contend that experiments or new discoveries cannot falsify a theory. Imre Lakatos, for instance, reminds his readers that "no experimental result can ever kill a theory; any theory can be saved from counterinstances either by some auxiliary hypothesis or by a suitable reinterpretation of its terms." Imre Lakatos, "Falsification and the Methodology of Scientific Research Programmes," in Lakatos and Allan Musgrave, eds., Criticism and the Growth of Knowledge (Proceedings of the International Colloquium in the Philosophy of Science, V.4 [Cambridge: Cambridge Univ. Pr., 1970]), p.116.

11. Nazli Choucri and Robert C. North, Nations in Conflict: National Growth and International Violence (San Francisco: W. H. Freeman, 1975), p.302. 
12. Kenneth N. Waltz, Theory of International Politics (Reading, Mass.: Addison-Wesley, 1979), p.9.

13. Ibid.

14. Fred Hoyle, Man in the Universe (New York: Columbia Univ. Pr., 1966), p.24.

15. Robin Horton, "African Traditional Thought and Western Science," Africa 37:51, 53 (1967).

16. Herbert Luthy, "Once Again: Calvinism and Capitalism," in S. N. Eisenstadt, ed., The Protestant Ethic and Modernization: A Comparative View (New York: Basic Books, 1968), p.124-25.

17. Stanislav Andreski, "Method and Substantive Theory in Max Weber," in S. N. Eisenstadt, ed., The Protestant Ethic and Modernization: A Comparative View (New York: Basic Books, 1968), p.35.
18. Carl A. Rogers, "Toward a Theory of Creativity," in S. I. Hayakawa, ed., A Review of General Semantics (New York: Harper Bros., 1959), p.178.

19. Michael Polanyi, Personal Knowledge: Towards a Post-Critical Philosophy (New York: Harper, 1964).

20. I owe this notion to Richard C. Phillips. For more details, see Richard C. Phillips, Teaching for Thinking High School Social Studies (Reading, Mass.: Addison-Wesley, 1974), p.129.

21. Ibid.

22. Howard Sherman, "Dialectics as a Method," Insurgent Sociologist 6, no.4:57 (1976).

23. Lakatos, "Falsification," p.125.

24. Phillips, Teaching, p.117. 